\title{
Influence of Charge-Compensating Ions on the Luminescence of Vanadium-Activated Sulfates
}

\author{
G. BLASSE AND G. P. M. VAN DEN HEUVEL \\ Physical Laboratory, Sorbonnelaan 4, Utrecht, The Netherlands
}

Received May 23, 1975

\begin{abstract}
Samples $\mathrm{CaSO}_{4}-\mathrm{V}^{5+}, \mathrm{Me}^{3+}$ show mainly unassociated-vanadate emission if $\mathrm{Me}^{3+}$ is smaller than the $\mathrm{Ca}^{2+}$ ion and mainly associated-vanadate emission if $\mathrm{Me}^{3+}$ is about as large as the $\mathrm{Ca}^{2+}$ ion. Samples $\mathrm{MgSO}_{4}-\mathrm{V}^{5+}, \mathrm{Me}^{3+}$ show efficient yellow emission at room temperature.
\end{abstract}

\section{Introduction}

Recently the presence of associates $\mathrm{V}^{5+}$ $\mathrm{Ln}^{3+}$ in $\mathrm{CaSO}_{4}$ and the occurrence of energy transfer in these associates has been reported $(1,2)$. Vanadium occupies the tetrahedral sulfur site and is charge-compensated by a trivalent lanthanide ion on one of the nearestneighbor calcium sites. In this paper, we describe the luminescence of $\mathrm{CaSO}_{4}-\mathrm{V}^{5+}$, $\mathrm{Me}^{3+}$, where $\mathrm{Me}^{3+}$ stands for trivalent ions smaller than the lanthanides. In addition, efficient vanadate luminescence in $\mathrm{MgSO}_{4}$ is reported.

\section{Experimental}

Samples were prepared and characterized as described before. Dope concentrations were 0.1 or 0.3 at $\%$. Optical measurements were performed as in $(l, 2)$.

\section{Results and Discussion}

(a) $\mathrm{Ca}_{1-x} M e_{x} \mathrm{~S}_{1-x} \mathrm{~V}_{x} \mathrm{O}_{4}(M e=\mathrm{Al}, \mathrm{Sc}, \mathrm{Fe}, \mathrm{Ga})$

The luminescence properties of these samples do not depend strongly on the nature of $M e$. Therefore, only the results for $M e=\mathrm{Ga}$ are given. Below room temperature a greenish emission can be excitcd by uv excitation. Figure 1 shows some excitation and emission spectra at LHeT. These reveal a rather complex luminescence behavior due to over- lapping excitation and emission bands; there seem to be at least two excitation bands, one at about $280 \mathrm{~nm}$ and the other at about $250 \mathrm{~nm}$. Excitation into the latter yields an extra emission shoulder in the short-wavelength part of the spectrum (see Fig. 1). This shoulder was not detected for the $\mathrm{Fe}^{3+}$-doped sample.

This behavior differs from that observed for $\mathrm{CaSO}_{4}-\mathrm{V}^{5+}, \mathrm{Ln}^{3+}(\mathrm{Ln}=\mathrm{Y}, \mathrm{La}, \mathrm{Gd}, \mathrm{Lu})$, where the emission band peaks at $465 \mathrm{~nm}$ and the excitation band peaks at $255 \mathrm{~nm}$. The emission band of uncompensated $\mathrm{CaSO}_{4}-\mathrm{V}^{5+}$ has its maximum at $520 \mathrm{~nm}(1,2)$. A simple explanation for these differences is the following. If the compensating trivalent cation is one of the lanthanides, we have associates $\mathrm{V}^{5+}-L n^{3+}$ as shown in $(1,2)$ with the $465 \mathrm{~nm}$ emission band; if the compensating cation is $\mathrm{Al}, \mathrm{Sc}, \mathrm{Fe}$, or $\mathrm{Ga}$, the degree of association is much lower. The $\mathrm{V}^{5+}$ ion occurs partly as a "free" (unassociated) $\mathrm{V}^{5+}$ ion with an emission band at $520 \mathrm{~nm}$ (and an excitation band at about $280 \mathrm{~nm}$ ) and partly as an associate $\mathrm{V}^{5+}-\mathrm{Me}^{3+}$ with bluish emission (excitable with $250 \mathrm{~nm}$ radiation) as in the case of the $\mathrm{V}^{5+} \mathrm{Ln}^{3+}$ associates.

A high degree of association in the case of these $M e^{3+}$ ions is improbable, because an associate $\mathrm{V}^{5+}-\mathrm{Fe}^{3+}$ is not expected to luminesce. The "killing-action" of transition metal ions on emissions like those of the vanadate group is well known (3). This also 


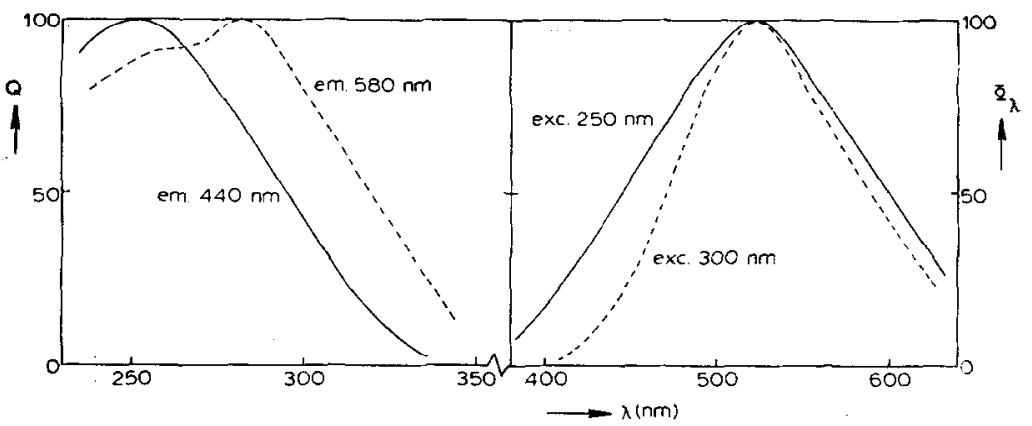

FIG. 1. Left: Relative excitation spectra of the 440 and $580 \mathrm{~nm}$ emission of $\mathrm{Ca}_{0.997} \mathrm{Ga}_{0.003} \mathrm{~S}_{0.997} \mathrm{~V}_{0.003} \mathrm{O}_{4}$ at $5^{\circ} \mathrm{K}$ ( $Q$ gives the relative quantum output). Right: Spectral energy distribution of the emission of this sample at $5^{\circ} \mathrm{K}$ under 250 and $300 \mathrm{~nm}$ excitation. ( $\Phi_{\lambda}$ gives the spectral radiant power per constant wavelength interval in arbitrary units.)

explains the absence of the blue shoulder in the case of the $\mathrm{Fe}^{3+}$-doped sample.

The degree of association of $\mathrm{V}^{5+}$ and $\mathrm{Me}^{3+}$ ions in $\mathrm{CaSO}_{4}$ depends, therefore, on the ionic radius of the $\mathrm{Me}^{3+}$ ions. If these are of about the same size as or larger than the $\mathrm{Ca}^{2+}$ ion, the degree of association is high; if their size is considerably smaller, the degree of association is low. The influence of the association degree on the vanadate luminescence is drastic.

(b) $\mathrm{Mg}_{1-x} M e_{x} \mathrm{~S}_{1-x} \mathrm{~V}_{x} \mathrm{O}_{4}(M e=\mathrm{Al}, \mathrm{Cr}, \mathrm{Fe})$

In view of the results of the calcium system and the small difference between the ionic radii of $\mathrm{Al}^{3+}$ and $\mathrm{Mg}^{2+}$ we expected that $\mathrm{Al}^{3+}$ and $\mathrm{V}^{5+}$ would be associated in $\mathrm{MgSO}_{4}$. At $300^{\circ} \mathrm{K}$, samples $\mathrm{MgSO}_{4}-\mathrm{V}^{5+}, \mathrm{Al}^{3+}$, and $\mathrm{MgSO}_{4}-\mathrm{V}^{5+}$ show efficient yellow emission under long as well as shortwave uv excitation. At $300^{\circ} \mathrm{K}$, samples $\mathrm{MgSO}_{4}-\mathrm{V}^{5+}, \mathrm{Cr}^{3+}$ and $\mathrm{MgSO}_{4}-\mathrm{V}^{s+}, \mathrm{Fe}^{3+}$ show yellow emission under shortwave uv excitation only. $\mathrm{MgSO}_{4}-$ $\mathrm{V}^{5+}, \mathrm{Cr}^{3+}$ shows strong red emission under longwave uv excitation at liquid $\mathrm{N}_{2}$ temperature.

In Fig. 2 we have drawn some representative excitation spectra and in Fig. 3 emission spectra. The following facts are noteworthy.

(i) The spectra for $\mathrm{MgSO}_{4}-\mathrm{V}^{5+}, \mathrm{MgSO}_{4}-$ $\mathrm{V}^{5+}, \mathrm{Cr}^{3+}$ and $\mathrm{MgSO}_{4}-\mathrm{V}^{5+}, \mathrm{Fe}^{3+}$ are practically the same.

(ii) The excitation spectra of $\mathrm{MgSO}_{4}$ $\mathrm{V}^{5+}, \mathrm{Al}^{3+}$ show an excitation band with a maximum at $330 \mathrm{~nm}$ that is not present in the spectra of samples with other compensating ions.

It seems probable that in $\mathrm{MgSO}_{4}$ a large number of different luminescent vanadate centers is present. Our samples crystallize in the low-temperature $\mathrm{MgSO}_{4}$ structure (the $\mathrm{CrVO}_{4}$ structure) with $\mathrm{Mg}^{2+}$ in octahedral and $\mathrm{S}^{6+}$ in tetrahedral coordination (4). There is only one crystallographic position for $\mathrm{Mg}$ as well as for $\mathbf{S}$. From our results we deduce the following approximate model. The emission and excitation spectra observed for $\mathrm{MgSO}_{4}-\mathrm{V}^{5+}$ and the $\mathrm{Cr}^{3+}$ and $\mathrm{Fe}^{3+}$ compensated samples are due to "free" $\mathrm{V}^{5+}$ ions. In fact these spectra show an analogy with the spectra for the "free" $V^{5+}$ ions in $\mathrm{CaSO}_{4}$. (Compare Fig. 1 with Figs. 2 and 3.) Any associates $\mathrm{V}^{5+}-\mathrm{Cr}^{3+}$ and $\mathrm{V}^{5+}-\mathrm{Fe}^{3+}$ are not

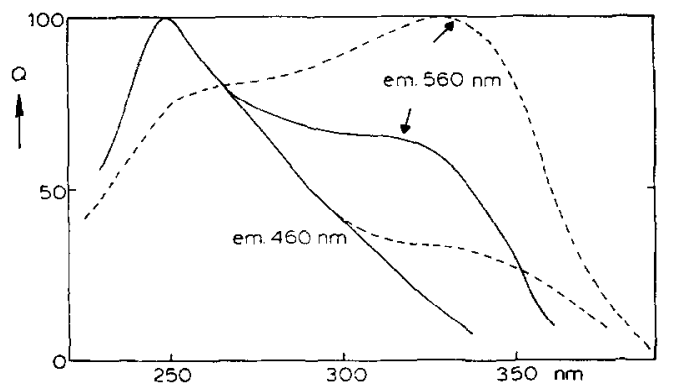

Fig. 2. Relative excitation spectra of the 460 and $560 \mathrm{~nm}$ emission of $\mathrm{Mg}_{0.997} \mathrm{Al}_{0.003} \mathrm{~S}_{0.997} \mathrm{~V}_{0.003} \mathrm{O}_{4}$ (broken lines) and $\mathrm{Mg}_{0.997} \mathrm{Cr}_{0.003} \mathrm{~S}_{0.997} \mathrm{~V}_{0.003} \mathrm{O}_{4}$ (solid lines) at room temperature. Curves for $\mathrm{MgSO}_{4}-\mathrm{V}$ $(0.3$ at $\%)$ are identical to the curves for the $\mathrm{Cr}^{3+}$ sample. 


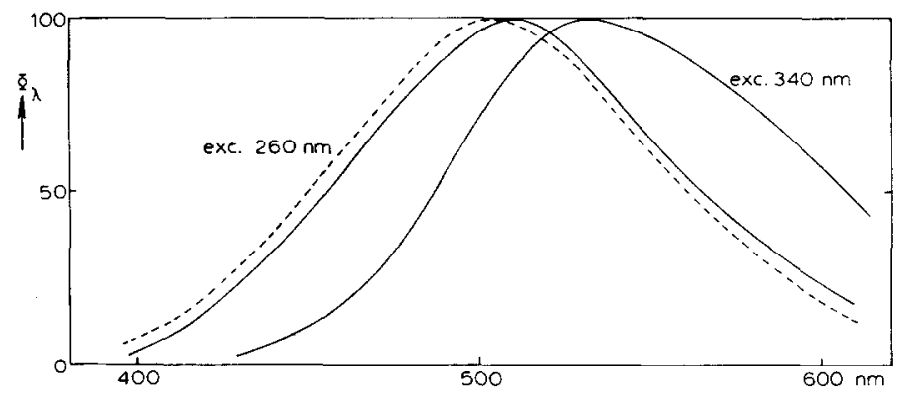

FIG. 3. Spectral energy distribution of the emission of $\mathrm{Mg}_{0.997} \mathrm{Cr}_{0.003} \mathrm{~S}_{0.997} \mathrm{~V}_{0.003} \mathrm{O}_{4}$ (broken line) under $260 \mathrm{~nm}$ excitation and of $\mathrm{MgSO}_{4}-\mathrm{V}(0.3$ at \%) (solid lines) under 260 and $340 \mathrm{~nm}$ excitation at room temperature.

expected to luminesce. The $\mathrm{V}^{5+}$ center in $\mathrm{MgSO}_{4}-\mathrm{V}^{5+}, \mathrm{Al}^{3+}$ with the excitation band at $330 \mathrm{~nm}$ is then probably a $\mathrm{V}^{5+}$ ion associated with $\mathrm{Al}^{3+}$. Evidence for this follows from the observation that at $300^{\circ} \mathrm{K}, 330 \mathrm{~nm}$ excitation yields efficient luminescence for the $\mathrm{Al}^{3+}$ sample, but not for the $\mathrm{Cr}^{3+}$ and $\mathrm{Fe}^{3+}$ samples. At lower temperatures, however, the $\mathrm{Cr}^{3+}$ emission (red) can be excited into this band (energy transfer in a possible $\mathrm{V}^{5+}-\mathrm{Cr}^{3+}$ associate). Direct excitation of the $\mathrm{Cr}^{3+}$ ion, however, cannot be excluded.

It is remarkable that in $\mathrm{MgSO}_{4}$ the associate has its spectra (especially the excitation band) at longer wavelengths than the free $\mathrm{V}^{5+}$ ion, whereas in $\mathrm{CaSO}_{4}$ the situation is reversed. This may indicate that the associate in $\mathrm{MgSO}_{4}$ is different from that in $\mathrm{CaSO}_{4}$ where the compensating ion in the associate occupies a regular (calcium) lattice site. It seems impossible to achieve in $\mathrm{MgSO}_{4}$ an association that is so complete as in $\mathrm{CaSO}_{4}$.

Finally, we may add that the yellow emission of $\mathrm{V}^{5+}$ in $\mathrm{MgSO}_{4}$ is probably the same as mentioned in (5) for $\mathrm{V}_{2} \mathrm{O}_{7}^{4-}$ in $\mathrm{MgSO}_{4}$.

\section{References}

1. W. HoRdIJK AND G. BLASSE, J. Luminescence 6, 137 (1973).

2. W. T. Draai and G. Blasse, Phys. Stat. Sol.21,569 (1974).

3. F. A. KRöGER, "Some Aspects of the Luminescence of Solids," Elsevier, Amsterdam (1948).

4. R. W. G. WyскоғF, "Crystal Structures," 2nd ed., Vol. 3, Interscience, New York (1965).

5. Y. Kotera, M. Yonemura, and T. Sekine, $J$. Electrochem. Soc. 108, 540 (1961). 